\title{
Geospatial Model as Strategy to Prevent Forest Fires: A Case Study
}

\author{
Marín Pompa-García ${ }^{1}$, Maico Zapata-Molina ${ }^{1}$, Ciro Hernández-Díaz ${ }^{2}$, Efraín Rodríguez-Téllez ${ }^{1}$ \\ ${ }^{1}$ Facultad de Ciencias Forestales, Universidad Juárez del Estado de Durango (UJED), Victoria de Durango, México; ${ }^{2}$ Instituto de \\ Silvicultura e Industria de la Madera, Universidad Juárez del Estado de Durango (UJED), Victoria de Durango, México. \\ Email: mpgarcia@ujed.mx,maicozapata@hotmail.com,jciroh@ujed.mx, efrainrodriguezt@hotmail.com
}

Received July $1^{\text {st }}, 2012$; revised July $31^{\text {st }}, 2012$; accepted August $27^{\text {th }}, 2012$

\begin{abstract}
The forests of the State of Durango have been severely affected by fires in recent years. Early detection of fires through watchtowers is essential. In this work a geospatial model was generated to optimize strategic visualization points, using a GIS environment. Analysis of the area of visibility was developed by integrating a digital model of elevation and a plant cover map. The resulting distribution generates more than 50\% coverage of the studied area, in points that were not always the highest. It was concluded that this strategy would permit to increase the efficiency, mainly favoring the communities of pine, whose economic importance would justify the required investment.
\end{abstract}

Keywords: Viewshed Analysis; Watchtowers; Forest Fires

\section{Introduction}

Faced with the need to preserve their forests, the Pueblo Nuevo ejido land owners have decided to install surveillance towers to develop permanent and effective actions in the prevention of forest fires. According to [1], the ejido forests have been severely affected by the fire; a total of 8522 hectares were burned in the period 20012010.

The main concern is that in times of rain shortage the risk of fire increases. At the global level, $95 \%$ of all fires are caused by human activities [2].

Currently there are technologies which allow analyzing and characterizing the terrain. GIS technology allows integrating tools for analyzing data for the prevention, planning and management of forest fires [3]. One of these applications is the analysis of visual basins. Several authors have recognized that the modern scientific technologies and procedures facilitate the development of techniques for detecting and monitoring forest fires, characterized by a combination of geographic information systems and spatial data on forest fires [4,5]. According to [6] various geographical conditions must be evaluated, as the positions that maximize visual coverage, taking into account that the areas of high-altitude should be included.

Given that in the State of Durango still no studies have been conducted about the analysis of spatial visibility, the objective of the present study was to develop a proposal of distribution of observation points which maxi- mize the visible surface, in the forests of the southwest of the State of Durango, Mexico.

\section{Materials and Methods}

\subsection{Stduy Area}

The selected study area is located to the southwest of the State of Durango. Its geographical coordinates are between $23^{\circ} 07^{\prime}$ and $23^{\circ} 39^{\prime}$ North latitude and $105^{\circ} 12^{\prime}$ and $105^{\circ} 46^{\prime}$ West longitude. The total surface is 240,739 ha, with a rugged topography in a system of plateaus associated with ravines and altitude from 500 to 2800 meters above sea level. Soils have their origin in the weathering of igneous rocks. The main land uses are the agricultural, livestock and forestry [7]. Most of the ecosystems are communally owned, although there are some privately owned. The climates are: $\mathrm{C}(\mathrm{w} 2)$, temperate, sub humid, rains of summer $5 \%$ to $10.2 \%$ per annum; (A)C(w2), semi warm, temperate sub humid, rains of summer $5 \%$ to $10.2 \%$ per annum; $\mathrm{Cb}^{\prime}(\mathrm{w} 2)$, tempered, semi cold, with long sub humid fresh summer, with summer rains from $5 \%$ to $10.2 \%$ per annum; Awl, warm sub humid, summer rains of $5 \%$ to $10.2 \%$ per annum; $C(w 2)$, temperate, sub-humid, summer rains of $5 \%$ to $10.2 \%$ per annum [8].

\subsection{Sequential Process}

To achieve the established goal a digital elevation model scale 1:50,000 was used, in raster format of two bits per data of the UTM coordinate system. The digital elevation 
model (DEM) is a data file that contains an array of elevation values $[9,10]$. One of the common uses of the DEM is the analysis of visual basins, which is the identification of land areas which can be seen from a particular point of the ground [10].

The resulting values correspond to the orthometric heights expressed in whole units in meters and are relative to the average sea level, based on the World Geodetic System 1984, Zone 13 N. Using the tools described above a plane was drawn with the physical characteristics of the land and 6 points were located, as shown in Figure 1.

The next step consisted of the combination of locations of the points mentioned above and with this, to see the total area of visibility; then a map with the total of visual areas was drawn and superimposed on the map of the national forest inventory of the year 2000, carried out by [11]. This was done in order to determine the types of vegetation visible from the watchtowers. The "viewshed" application of [12] was used in the surface analysis.

\section{Results}

Six points of highest altitude were placed in the study area. Their coordinates are shown in Table 1, while the visibility area covered by the towers is shown in Figure 2.

From the visibility points different types of vegetation are observed, ranging from coniferous forests, passing

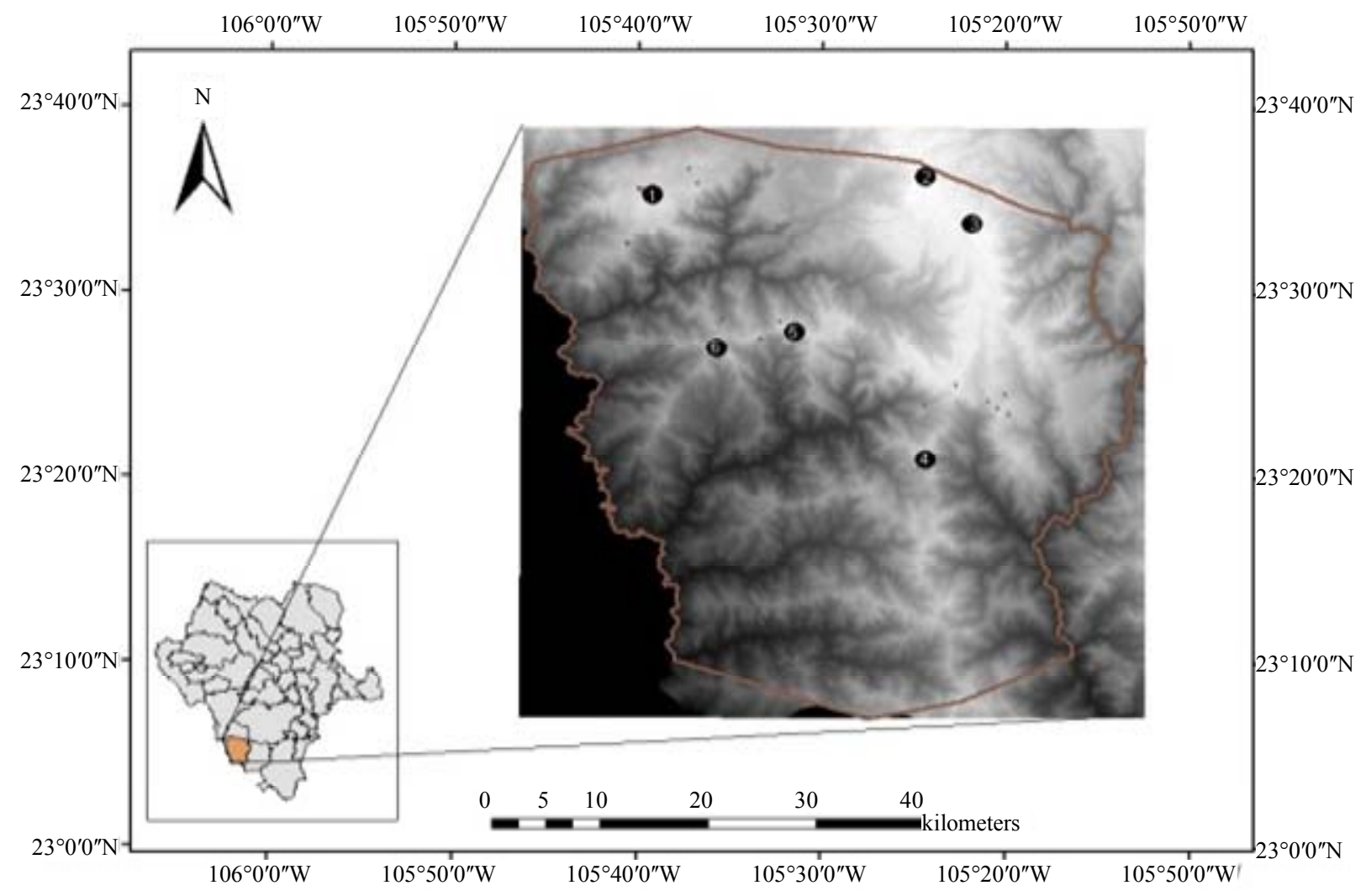

Figure 1. Ejido Pueblo Nuevo with location of proposed points for the detection of forest fires.

Table 1. Points for the installation of watch towers.

\begin{tabular}{ccc}
\hline Location & Geographical coordinates & Altitude (masl) \\
\hline Point 1 & $105^{\circ} 39^{\prime} 12.272^{\prime \prime} \mathrm{W} 23^{\circ} 35^{\prime} 21.192^{\prime \prime} \mathrm{N}$ & 2669 \\
Point 2 & $105^{\circ} 24^{\prime} 29.447^{\prime \prime} \mathrm{W} 23^{\circ} 36^{\prime} 25.672^{\prime \prime} \mathrm{N}$ & 2974 \\
Point 3 & $105^{\circ} 23^{\prime} 38.977^{\prime \prime} \mathrm{W} 23^{\circ} 16^{\prime} 44.944^{\prime \prime} \mathrm{N}$ & 2923 \\
Point 4 & $105^{\circ} 24^{\prime} 6.527^{\prime \prime} \mathrm{W} 23^{\circ} 21^{\prime} 4.544^{\prime \prime} \mathrm{N}$ & 2356 \\
Point 5 & $105^{\circ} 31^{\prime} 29.36^{\prime \prime} \mathrm{W} 23^{\circ} 27^{\prime} 55.542^{\prime \prime} \mathrm{N}$ & 2584 \\
Point 6 & $105^{\circ} 35^{\prime} 42.805^{\prime \prime} \mathrm{W} 23^{\circ} 27^{\prime} 4.729^{\prime \prime} \mathrm{N}$ & 2504 \\
\hline
\end{tabular}




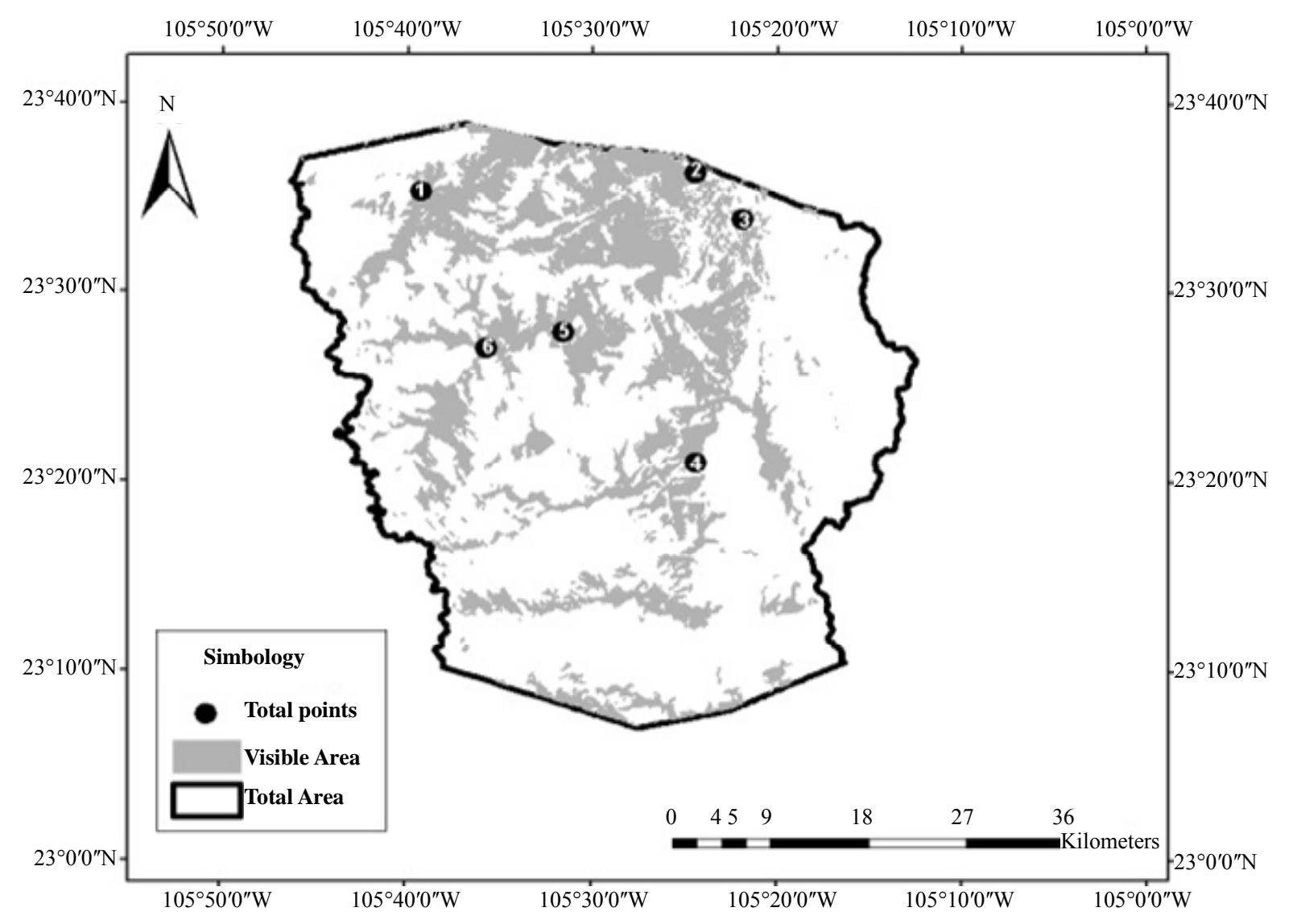

Figure 2. Viewpoints distribution and their coverage of the study area.

through conifers and hardwoods associations and also rain fed crop areas. The point 1 had an effectiveness of $50.54 \%$, points 5 and 6 reached together effectiveness of point 6 in a $57.35 \%$; on the other hand the three remaining points $(2,3$ and 4$)$ show a small weighted percentage $7.76 \%$ which gives as a result not to be considered for the possible installation of towers (Figure 3).

The classification of forest land in relation to the coverage by vegetation type, from the proposed points, is shown in Table 2.

\section{Discussion}

There are no studies of visual basins in the State of Durango and little has been considered the installation of surveillance towers. The importance of these is crucial to the detection and immediate combat of fires.

The results show that the visibility from the three main viewpoints reaches an effectiveness of $52.95 \%$, in such a way that the remaining $47.05 \%$ of the surface is not directly visible. It should be noted that in the literature it is reported that an $80 \%$ of the area should be covered, which is confirmed by Pompa et al. (2010). Although Almeida et al. (2007) recommended including the areas of greater height, oddly in the present study points 2 and
3, which have an elevation exceeding 1900 meters above sea level, account for only $11.40 \%$ and $1.82 \%$ of the coverage respectively, which demonstrates that not always the highest areas are necessarily the best.

Taking into consideration the location of the visual points, the covered area corresponds to coniferous forest in a $71.09 \%$, which justifies the establishment of observation towers given the economic and ecological importance of these areas. However, lower regions occupied by deciduous and sub deciduous vegetation have a smaller range of visibility, because they are found on slopes ranging from 300 to 1400 meters above the level of the sea.

Regardless of the visual area covered, it is advisable to have operational staff for the towers of surveillance, communications equipment and complementary tools, in order to improve the work of detection and combat of forest fires.

\section{Conclusions}

The development of procedures and analysis of visibility by means of digital elevation models, allowed obtaining reliable information regarding the coverage of observation areas on the forest resources of the ejido Pueblo Nuevo. 
Table 2. Visual surface by type of vegetation.

\begin{tabular}{cccc}
\hline Vegetation type & Total area (ha) & Visual area (ha) & Percentaje \\
\hline Rainfed agriculture & 2558 & 1606 & 62.81 \\
Coniferous forest & 67690 & 48123 & 71.09 \\
Softwood and hardwood forest & 74142 & 40556 & 54.70 \\
Hardwood forest & 53051 & 23822 & 44.91 \\
Induced and cultivated grasslands & 7887 & 2443 & 30.98 \\
Deciduous and semi-deciduous forest & 22649 & 4165 & 18.39 \\
\hline
\end{tabular}

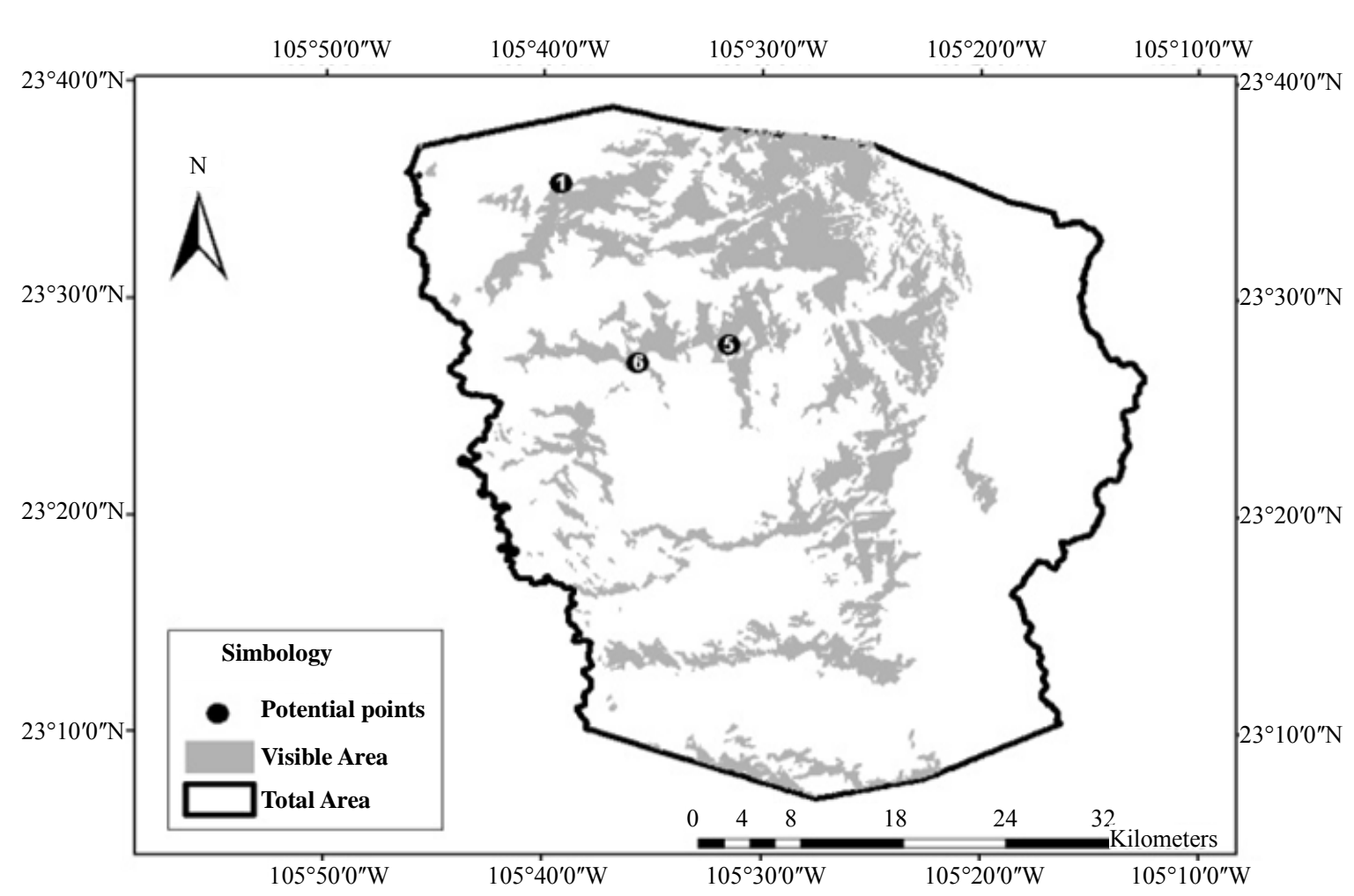

Figure 3. Visibility area which can be reached with the location of just three potential viewpoints.

It has been concluded that a $52.95 \%$ of the total of the visible surface meets the stated objectives. Primarily the communities of pine forests are favored, which because of their economic importance would justify the necessary investment. Not to mention that an efficient system of forest fires detection should also include a supplement supported by ground patrols, radio systems and remote sensing tools.

For the regions that are not visible, it is worth mentioning that these are areas in which the recurrence of fire is very low, usually covered with grasslands, agriculture and low jungle. Although these do not mean they deserve less attention.

\section{Acknowledgements}

The work was conducted within the framework of Aca- demic Mobility supported by the UJED \& CONACyT. We would like to thank the support given by the technical head of the Ejido "Pueblo Nuevo" who supported the provision of data used in this study. Also we recognize to ISIMA and COCYTED in Durango for financial assistance.

\section{REFERENCES}

[1] CONAFOR, "Weekly Report of Results of Forest Fires 2010. Coordination for Conservation and Restoration. Management Office of Forest Fire Protection," 2010. http://www.conafor.gob.mx:8080/documentos/docs/10/83 Repote\%20Semanal\%202010.pdf

[2] FAO, "Forest Fires Devastate More and More Forests around the World," 2003. http://www.fao.org/spanish/newsroom/news/2003/21962es.html 
[3] G. M. Pompa, M. R. Solís, T. E. Rodríguez, A. A. Pinedo, F. D. Ávila, D. J. C. Hernández and B. E. Velasco, "Viewshed Analysis for Improving the Effectiveness of Watchtowers, in the North of Mexico," Open Forest Science, Vol. 3, 2010, pp. 17-22. doi:10.2174/18743398601003010017

[4] P. J. Palacio, L. G. Luna and L. M. Macías, "Fire Detection in Mexico Using AVHRR Images (1998 Season). Geographical Research," Bulletin of the Institute of Geography, Vol. 38, 1999, pp. 7-14.

[5] H. Wu, M. Pan, L. Yao and B. Luo, "A Partition-Based Serial Algorithm for Generating Viewshed on Massive DEMs," International Journal of Geographical Information Science, Vol. 21, No. 9, 2007, pp. 955-964. doi:10.1080/13658810601034218

[6] P. J. Almeida, P. Relvas, L. Silva, X. F. Catry, C. F. Rego and A. T. Santos, "Wildfires: Portuguese Lookout Towers Network Optimization Using Automatic Positioning Algorithms," Proceedings of the International Wild Land
Fire Conference, Seville, 13-17 May 2007.

[7] R. Meraz, "Forest Management Program," Forest Technical Services in Ejido Pueblo Nuevo, 1998, 215 p.

[8] G. M. Pompa, "Geographic information System of the Ecosystems of Durango," 2012. http://www.ujed.mx/sigeed/ Inicio.aspx

[9] S. Aronoff, "Geographic Information Systems: A Management Perspective," WDL Publications, Ottawa, 1995, p. 121.

[10] I. Heywood, S. Cornelius and S. Carver, "An Introduction to Geographical Information Systems," 2nd Edition, Prentice Hall, Inc., London, 2002, pp. 128-129.

[11] SEMARNAT, "Cartographic Analysis of the National Forest Inventory Using Satellite Images LANDSAT," SEMARNAT, México, 2000.

[12] Environmental Systems Research Institute (ESRI), "Software ArcMap 9.2," ESRI, Redlands, 2008. 